\title{
SCIDiC
}

International Journal of Anatomy and Applied Physiology (IJAAP)

ISSN: 2572-7451

\section{Fascia The Universal Singularity Of Biotensegrity The Dark Matter Of Our Inner Cosmos}

\author{
Research Article
}

John Sharkey*

Faculty of Medicine, Dentistry and Clinical Sciences, University of Chester/NTC, 15-16aSt Joseph's Parade, Dorset St, DO7 FR6C, Dublin, Ireland.

\section{Abstract}

Embryology is key to understanding liquid and solid fascia, the universal singularity of our inner cosmos that is analogous to dark matter. Fascia continuity is verified by our form, continuous and unbroken. Since the earliest origins humans have pondered meaningful questions involving our place in the cosmos and how we arose from it. "for dust thou art, and unto dust shalt thou return”, Genesis 3:19. Evolutionists and religious philosophers alike support the proposal that it is star dust from whence we came. Embryologists and anatomists can agree that whatever 'dust' is used in human creation it is the embryo that grows itself. No surgical intervention is required to attach limb buds or implant an organ. Embryo's themselves grow the necessary structures to support life and motion. To appreciate the singularity that is fascia this paper provides observations made during dissections, supported by embryological, and tensegrity based principles shaping our inner cosmos. Embryology provides evidence of continuity through the singularity that is fascia, a liquid crystal matrix. All liquid crystals operate on a spectrum of hardness to softness, without straying from their fundamental category of soft matter. All liquid in the human body (with the exception of urine) is bound. That is, as variations on the liquid crystal theme, as volumes. Even bone begins as a cartilaginous placeholder and "crystalises" in to harder cases, containing soft matter within their more crystalline arrangements. Biotensegrity is a model that begins to explain the living architecture of cells, tissues, organs and organ systems. Tensegrity based architecture facilitates forces required for nutrition and cellular diversity [i.e. mechanotransduction] leading to connective tissue specialisation [e.g. blood, lymph, fascia, bone] as a resulting combination of genetic and epigenetic expression. Fascia distributes tensional and compressional energy necessary to provoke physiology, metabolism, motion and biochemical responsiveness. Based on a synergy of genetics and epigenetics, nature's creativity results in complex shapes, patterns and processes. DNA and RNA are orphan's doomed to inactivity without the non-linear, force specific, oscillatory waves provided by epigenetic mechanisms emerging as a consequence of their pre-stressed cellular environment.

The instructions for gene expression within DNA, is nurtured and informed by the universal singularity that is fascia. This short paper provides evidence concerning the model-dependent reality of biotensegrity and presents an argument for fascia as the singularity of the inner cosmos.

Keywords: Embryology; Fascia; Biotensegrity; Epigenetics; DNA; Anatomy; Dissection.

\section{Introduction}

Tensegrity principles express the integrated tension/compression based architectural blueprint of living cells and the morphological influences on fascia's phenotypic plasticity $[1,2,3]$. The term tensegrity is a blending, or compression, of two words, namely tension and integrity [4]. Only three triangulated polyhedra can support the construction of natural structures [Fuller 1975]. Fuller identified these polyhedra as the tetrahedron, octahedron and the icosahedron. Due to its stable nature, closest-packing ability and surface to volume ratio, the icosahedron tensegrity is considered most apt for sustaining life [6]. The original cell is a volume or sphere, that in geometric terms can be shown to be a highfrequency icosahedron [9]. As the most basic building blocks for life are themselves tensegrity icosahedron's the human construct is built on a scale-free system of tensegrity within tensegrity, from micro to macro [4]. Tensegrities do not contain joints, they are force distributing, energy efficient, constantly fine-tuning, tensioned systems, containing floating compression struts, dowels,

\footnotetext{
*Corresponding Author:

John Sharkey,

Faculty of Medicine, Dentistry and Clinical Sciences, University of Chester/NTC, 15-16aSt Joseph's Parade, Dorset St, DO7 FR6C, Dublin, Ireland.

E-mail: john.sharkey@ntc.ie
}

Received: March 03, 2021

Accepted: March 20, 2021

Published: March 22, 2021

Citation: John Sharkey. Fascia The Universal Singularity Of Biotensegrity The Dark Matter Of Our Inner Cosmos. Int J Anat Appl Physiol. 2021;07(02):179-184. doi: http://dx.doi.org/10.19070/2572-7451-2100033

Copyright: John Sharkey ${ }^{\circ} 2021$. This is an open-access article distributed under the terms of the Creative Commons Attribution License, which permits unrestricted use, distribution and reproduction in any medium, provided the original author and source are credited. 
rods or bars [7]. Biotensegrity is a term concocted by compressing portions of three words, namely biology, tension and integrity, uniting them as a portmanteau [7]. All living constructs, including viruses, have an underlying basal tone or pre-stress to their structure [e.g. myogenic, neurogenic] [1, 2]. Using a car engine analogy this means contractile tissues always have their engines running. Pre-tension allows for cell-cell communication and exchanges between systems, at all scales, creating structural hierarchies constituting extracellular matrix and cytoskeletal networks that traverse the macro to the microscale. Mechanotransduction is the exchange of appropriate forces translated by specific mechanotransductive molecules resulting in diverse activities including cell shape, metabolism, movement and biochemical responsiveness [i.e. gene expression] [1, 2]. Embryogenesis explains how living constructs start as single cells and develop in to a multicellular organism composed of ubiquitous tubes within tubes [8] as expressed in Figure 1.

Conception, involving the conjoining of one spermatocide and the female oocyte, can be described as a 'big bang'. Embryology has many similar connotations to the forming of the universe and the study of cosmology. If the laws of biotensegrity are to be applied to the inner cosmos, they must reflect the laws that govern the outer cosmos. Physical laws of forces and force transmission do not change, it is the nature of the self-developmental forming process that go through variations [9]. Embryology informs us that in as little as eight weeks we self-generate from a single cell zygote to a spheroid of cells and finally to an immature, but complete, multi-cellular organism [8]. A critical question concerning embryogenesis concerns how mesenchymal stem cells differentiate and specialise as distinct cell types. Timing [i.e. temporality] and location combine to determine cell fate [3] informing scientists that underlying cellular processes are non-linear, wholistic. Research has shown that all embryonic cells contain identical genetic sequalae [10]. Ingber demonstrated the critical role physical forces play in tissue development and ontogenesis [7]. Cells respond instantaneously to forces generated by fluid dynamics and other environmental factors resulting in biochemical responses [11]. All connective tissues originate from the inner cell mass, a clump of cells located within the blastocyst, a hollow ball that invaginates the uterine luminal epithelium to form the placenta [12]. At this point of development the blastocyst constitutes two primary germ layers, one inner layer [i.e. endoderm] and one outer layer [i.e. ectoderm]. These two skins or derms provide a virtual in-between space leading to the emergence of a third layer, the so-called mesoderm [13].

German anatomist and embryologist, Erich Blechschmidt, reported that the meso or middle layer, located between two skins [i.e. ectoderm and endoderm], formulated an already emerging human [14]. The mesoderm produces all of the somatic connective tissues and is, according to van der Wal [15], not a 'derm' but the origin of the primordial connective tissue mesenchyme [16]. Cell differentiation begins as early as day four [17]. Mesenchymal stem/stroma cells proliferate throughout the three dimensional microenvironment [or inner cosmos] of these so-called germ layers [18]. Mesenchymal stem cells play crucial roles in cell adhesion, migration, mitosis and differentiation. Multipotent mesenchymal stem cells develop in to a succession of cell lineages, including, but not limited to, chondrocyte, adipocyte, osteoblast, myoblast and neural cells, responding to mechanotransducive forces translated in to chemical cues [18].

Figure 1. Human dissection studies highlight the repetitious constructive nature of form reflected by the "tubes within tubes" analogy. Blood vessels, nerves, lymphatics, muscle fibers, bones, hair, ducts, digestive tract, bronchioles and ureters are all cylindrical tubular structures or varying shapes. Tubular architecture reflects first principles of tensegrity constructs. [Image: Sharkey, J. 2018].

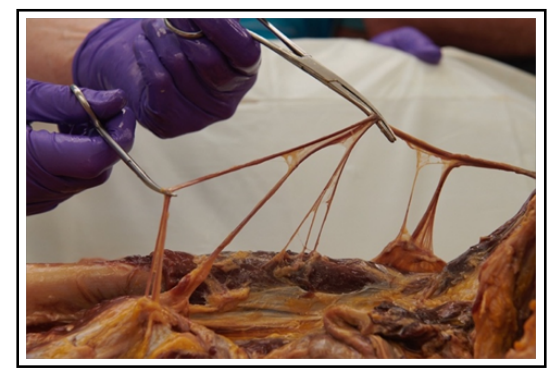

Figure $2 \mathrm{a}$ and $2 \mathrm{~b}$. Here we see a knee cap and femur void of its continuity and connectedness. Expansive forces provided by a tensegrity based multi-bar architecture, points to a model-dependent realism that healthy bones do not, as text books suggest, move closer together but rather retain and protect the joint space removing the notion that cartilage or meniscus is a shock absorber. $b$. In this image we see the evidence of 'bone on bone' pathology. This is a classical example of when the tensional integrity of a system is out of balance. In this case lack of integrity leads to a chronic painful condition described as chondromalacia patella or patellofemoral syndrome. [Images: Sharkey, J. 2017].

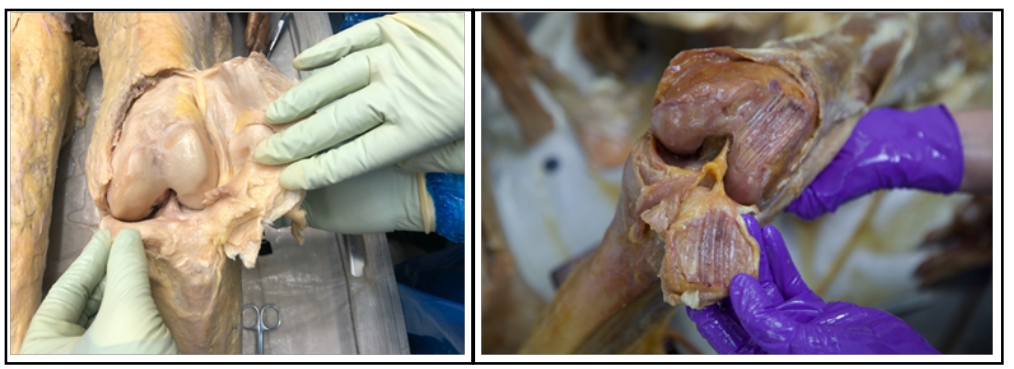


Multipotent mesenchymal stem cells migrate to functionally differentiate in to site specific cells on a body wide basis having dispersed [i.e. expansion] like dark matter throughout our inner cosmos[18]. Mesenchymal stem cells are fibroblastic, connective tissue progenitors representing a continuous body wide matrix consisting of cellular specialisation on a sequential temporal basis, that is, our fascial net [19]. This fascial net isa ubiquitous superhighway of double and triple helical fascial folds and in vagination's creating tubular cul-de-sac's and partitions allowing for exchange of forces through mechanotransduction [Ingber, 2008b, Ingber 1997]. An integral aspect of the facial singularity is the inclusion of biological fluids within the definition of fascia [7]. Blood, a fluid, is a connective tissue [20] but less appreciated as a fascial tissue.

The embryological histogenesis of blood is of mesoderm-derived blood islands [21].

Blood comprises a Non-Newtonian, non-linear capacity to morphologically respond on a time dependent scale ranging from fluid to solid [27]. Viewed in this way the human form can be seen as having no beginning or end and raises questions regarding the dogmatic language of parts, pin-joints, layers and discontinuity [7]. In this regard fascia, constructed of blood, osseofascial and myofascial tissue, becomes the primary constructive matrix of human form, and, similar to dark matter, it can be viewed as the singularity of our inner cosmos.

Anatomical art work displayed on the walls of European, Australian and Asian caves provide confirmation that interest in the study of anatomy has occupied mankind for millennia. According to recent research, based on available evidence, such interest has prevailed for no less than 25,000 years [22]. Dissection images appear in Italian texts from as early as 1345 [Guido de Vigevano, 1345]. Historical concepts, handed down from these earliest days of anatomical investigations must be challenged in the modern era. Of interest to the model of biotensegrity is the concept of levers in human anatomy. The lever model can be traced back to Archimedes of Syracuse, a Greek mathematician and engineer, who, using the logic of geometrics provided the evidence to support the law of the lever [28]. Such models attributed to human biomechanics diminish the role of fascia in locomotion and reduce our vision to one muscle one action void of continuity [4].

René Descartes [1596-1650], a French philosopher, cemented the notion of levers existing in human form and function based on the Cartesian method, a model that prevails to the current day. Descartes supported the supposition that one should not accept something as a fact unless it has been appropriately investigated and reasoned [23]. In Descartes famous 1637 tome he argues for the necessity to verify so-called facts based on detailed analysis of available evidence [24]. This plea from Descartes provides the motivation to revisit the model of levers in human form and report if anatomical investigation supports the lever model. Observationally, our limbs do seem to operate as levers utilising muscles to generate forces across joints [i.e. fulcrum or axis] to create movement. Investigating the hinge-like elbow joint the distance effort to the fulcrum is less than the distance from the load to the fulcrum. This provides the upper limb with a mechanical advantage of less than 1 . In a 2001 research investigation of rhesus monkeys the advantage was 0.001 [Merete Graham, 2001].

\section{Levers, Origins and Insertions}

"The sculpture is already complete within the marble block, before I start my work. It is already there, I just have to chisel away the superfluous material." Michelangelo di LodovicoBuonarrotiSimoni [1475-1564].

University and college Libraries throughout the world abound with the most eloquent anatomy text books containing exquisite, artistically manicured, antiseptic, yet educationally valuable, anatomical images. Having taken many hours to clean away the attached, but unwanted, fascial tissues one is left with an artists impression of a specific point of view. An artifact, an object, a part, an isolated 'thing' void of its continuity and connectedness [Figure 3]. Anatomy text books, in effect, are seen as the operating manual for human machines with images of structures, their boundaries and borders informing the reader that "this is how it operates". Yet biotensegrity focused cadaveric dissection could not endorse many of the truisms or dogma of what is still today a predominantly $17^{\text {th }}$ century anatomy [4]. Descartes, communicating with Mersenne on the topic of heartbeat [letter dated 1639] wrote that he was prepared to admit that if what he had written on the topic of the heart heat, cardiac cycle and refraction turned out to be false, he would admit that the rest of his philosophy was entirely worthless [16]. The model of levers in anatomy isgenerally credited to Descartes and his mechanistic view of the world which, remaining popular today, has proven to be more than merely ephemeral. Yet, while Descartes assertions on heart heat are no longer accepted, anatomy continues to describe points of articulation as mechanical 'joints'.

The $17^{\text {th }}$ century word 'Fulcrum', is of Latin origin [derivative of the verb 'fulcire'] with a meaning of 'to prop up', 'post of a couch', or alternatively, a prop or support' [29]. This suggests that

Figure 3. Taking many hours to clean away the attached, but unwanted skin and, fascial tissues one is left with an artist's impression providing one specific point of view. An artifact, an object, a part, an isolated 'thing' is void of the living reality of continuity and connectedness. While this specimen can be a useful educational aid it must be stressed this is an artistic view that requires the removal of the fascia net to better expose the neurovascular anatomy within. [Image; Special thanks to von Hagen's Plastinarium, Guben, Germany].

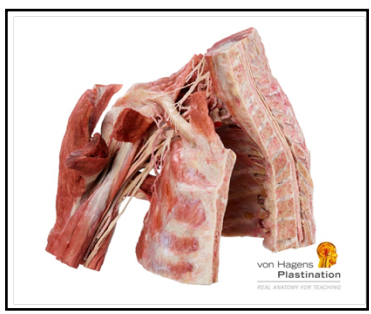


a fulcrum [or axis], as well as being a point around which movement takes place, is also a point of compression. Joint spaces, with their associated cartilage and meniscus tissue, are uniformly described as 'shock absorbers' while peer reviewed research has repeatedly demonstrated that synovial joints have a friction coefficient $[\mu]$ of the order $\sim 0.01$ or less. [25]. This, with the additional expansive forces provided by a tensegrity based multi-bar architecture, points to a model-dependent realism that healthy bones do not, as text books suggest, move closer together but rather retain and protect the joint space [Fig 2a]. This, at least, questions the notion that cartilage or meniscus is a shock absorber [26]. In Figure $2 b$ we see evidence of 'bone on bone' pathology. This is a classic example of when tensional integrity of a system is out of balance. In this case leading to friction, as bone compresses bone, a condition known as chondromalacia patella or patellofemoral syndrome [26].

Dissection of the elbow region clearly identified extensive ligamentous continuity and associated myofascial structures providing integrity to the elbow complex.

Three points of articulation were identified involving a radiohumeral portion with the proximal concaved portion of radius articulating with the capitulum of the articulating surface of lateral epicondyle of humerus. A humeroulnar articulation with the trochlea of the distal medial condyle of humerus articulating with the trochlear notch of ulnar. Finally the third articulation was between the ulnar radial notch and the radial notch of ulna [26]. Meticulous dissection, allowing intra-joint access, while leaving tendon inscriptions intact above and below the joint, allowed for the insertion of dental occlusive force measuring film in to the humeroulnar joint space. Passive flexion and extension of the joint was employed. Additionally, compressive forces through the long axis of the bones was also introduced. Joint space was not compromised and no indentation was evident on the occlusive film [26]. This rather simple observational assessment calls in to question the model of pin-joints in human anatomy and should serve as the motivation to others for more detailed investigation. The role of fascia in movement, dissipation of forces and protection of joint space is a superior hunting ground for explanations concerning the anatomy and mechanics of biomotion [9].

No clear demarcation of muscle origin or insertion was identified during biotensegrity focused dissection as tissues ran uninterrupted with change only observed in morphology [26].

Following hours of meticulous removal of associated connective tissues it was possible to provide a resemblance of origins and insertions as commonly depicted in popular anatomy tomes [26]. Similar to Michelangelo seeing, in advance, a form within the marble, the anatomist becomes the artist carving out a structure they wish to see emerge. Contrary to simplistic descriptions of origins and insertions biotensegrity focused dissection demonstrates the oversimplicity and erroneous nature of such a portrayal. When compared to the reality of form, the continuity of myofascial structures including osseofascial tissue, a new enlightened vision emerges [26]. In most instances muscle fibers fade as the tendon approaches densified osseofascial tissues without termination of the fascial component at any specific point. The tendon integrates as a densified osseofascial tissue only separable by scalpel or scissors. This supports the supposition by Snelson that bones float with in the fascial net [27].

On cross sectional dissection the fascia can be traced from the superficial aspect of the fascia profunda to the osseofascial periosteum without a break in what is a very obvious continuity [See Fig $4 \mathrm{a}$ and $4 \mathrm{~b}$. This "inside out anatomy" is also an artifact isolated and void of its continuity from the rest of the parts that constitute the whole. Appreciating connectiveness and continuity emerges from the act of dissection as without the act of cutting, the intact body shows itself whole and continuous [4].

It may be argued that origins and insertions serve as useful terms of convenience, especially for the early student of anatomy. Appreciating that muscles [i.e. myofascial structures] belong to a broader continuity and not simply to a point upon a bone, has important implications for surgeons and other allied medical practitioners. Appreciating the continuity of fascia as a singularity provides the foundation for understanding why migraine headaches can be as a result of insulted tissue in the lower limb [4]. Image $5 \mathrm{a}$ and $5 \mathrm{~b}$ are less antiseptic cadaver images showing a fascial contribution from the pectoralis minor to the under surface of pectoralis major and deltoideus [i.e. epimysial fascia] as it travels superior to the upper limb. The superior attachment, or insertion, of pectoralis minor is significantly wider than the so-called point of insertion, the coracoid process.

Continuity of the fascia profunda of pectoralis minor transitions to the costocoracoid membrane and condenses to form the costocoracoid ligament as it transitions beyond the clavipectoral fascia. As it journey's on, it melds and condenses becoming the suspensory axillary ligament. Here the fascia is more richly infused with fat on the lateral wall of the thorax. It then transitions as a ramus in an omni directional manner becoming brachial fascia and fascia of anterior thorax [26]. Pectoralis minor fascia is in continuity superficially and deep with the anterior and posterior

Figure $4 \mathrm{a}$ and $4 \mathrm{~b}$. On cross sectional dissection fascia could be traced from the superficial aspect of the fascia profunda to the osseofascialperiost without a break in what is a very obvious continuity. [Images: Fascia Net Plastination Project. Stecco, C., Schleip, R., Sharkey, J., and von Hagen's Plastinarium. 2018].

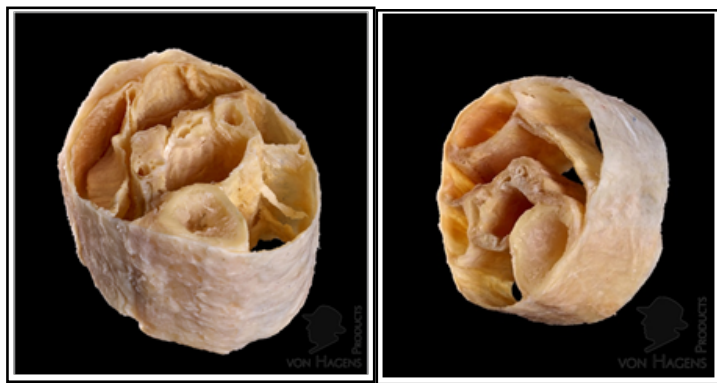


thorax, depicted in fig $5 \mathrm{a}$. The fasciculi arrangement of pectoralis minor is seen running in the same direction as the deeply placed external intercostals while the internal intercostal fascia is seen to run opposite providing a chiral, spiralling arrangement allowing for dissipation of forces in a non-linear fashion throughout the fascial web [26].

Figure $5 b$ demonstrates a laterally reflected scapula, removed off the posterior thorax, to reveal the slips of muscle fibre compartments and the associated septal tissues of muscle serratus anterior. It should be noted that blunt dissection, using the tips of fingers, was performed to disassociate the continuity of serratus anterior fascia with the deeper investing pre and intercostal fascia. Investigation of the fascial relationship of serratus anterior and the scapula clearly provides a very different picture to that of inserting on to the anterior vertebral border of scapula [26].

The scapula is invested and encapsulated within a fascial tube or pocket to which the fascia serratus anterior contributes without interruption to the continuity. Revealing a tendon, as in figure 6a, is only possible by removing the associated fascia, seen in figure 6b.

Biotensegrity focused dissection reveals the investing, continuous, connecting, separating [i.e. septal aponeurotic fascia], integratingnature of the fascial singularity. The myofascia is seen as the predominant source of attachment for muscle fibers while the harder osseofascial tissue provides the necessary architecture for energy efficient, anti-gravitational, co-ordinated motion.

Rather than the forearm flexors originating from the medial epicondyle they are continuous with the brachial and ante-brachial fascia. Fig 7 provides an informative image where it is clear to see how the ante-brachial fascia acts as a source of attachment, an aponeurosis, a septum and a mechanotransductive vehicle [26].

Bone has been described as a variation of fascia on a continuum of morphological expressions with variations along motifs of softness to hardness [30]. The embryological mesenchyme is the original matrix within which specialist cells and additional materials are deposited, such as hydroxyapatite, red blood cells, hepatic cells, plasma cells and muscle cells [4].

This uninterrupted organisation indicates a systems view of human anatomy supporting a unified vison that connects the suboccipital fascia to the endopelvic fascia descending to the feet contributing to holistic, harmonious function [31]. Respected surgeons and anatomists are now on record as stating that boundaries are man-made convenient concepts with no bases in reality [9]. Man-made boundaries have compounded the man-made notion that humans are constructed of parts. Anatomical investigations have repeatedly revealed the three dimensional ubiquitous nature of fascia, evident within, surrounding, protecting, separating, infiltrating and providing integrity to every aspect of our human form [32]. Leonardo da Vinci was convinced, as was Plato and Aristotle, that nature could provide solutions and inspiration

Figure 5a and 5b. Fascia Pectoralis minor is in continuity superficially and deep with the anterior thorax. $6 \mathrm{~b}$ demonstrates a laterally reflected scapula removed off the posterior thorax to reveal the slips of muscle fibre compartments and the associated septal tissues of muscle Serratus Anterior.[Images : Sharkey, J 2019].

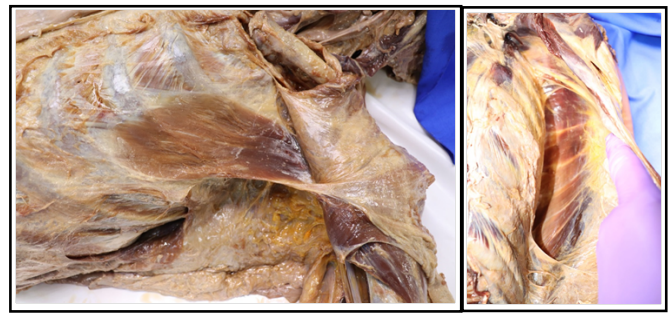

Figure $6 \mathrm{a}$ and $6 \mathrm{~b}$. Revealing a tendon, as in figure 6a, is only possible by removing the associated fascia, seen in figure $6 \mathrm{~b}$. Biotensegrity focused dissection reveals the investing and connective nature of the fascialsingularity. [Images: Sharkey, J.

2017].

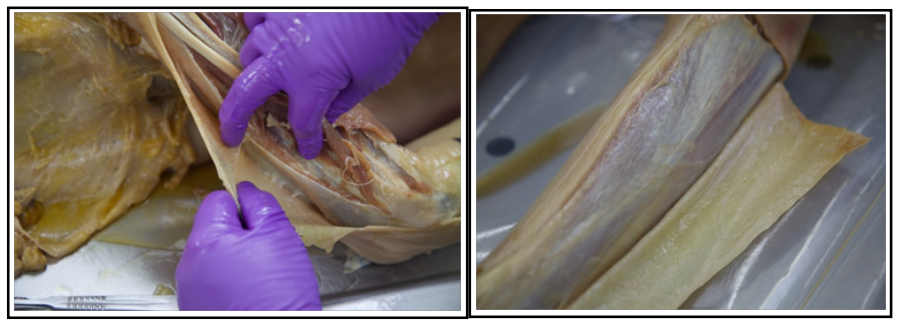

Figure 7. This image provides an informative view where it is clear to see how the ante-brachial fascia can act as source of attachment, an aponeurosis, a septum and a mechanotransductive vehicle.[Image: Sharkey, J. 2017].

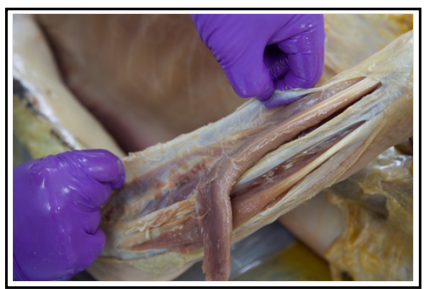


to understanding living forms [33]. After millions of years of evolution nature has established what works and what does not. Similarities to da Vinci's vison, [hundreds of years ahead of his time], can be seen in the modern scientific approach known as biomimicry. Biomimicry is the science of modelling structure on biological entities and processes with nature as mentor and model [34]. Researchers, over several decades, have demonstrated clear distinctions of tensegrity-based force transmission at the cellular level and at the fascial interfaces of all the connective tissues in the living body (i.e. membranous inter-fascial fluids on every scale) entirely based upon bound water principles [1]. This implies the same heterarchical and hierarchical developmental bases for all tissues. This structural reality of our fascia singularity reflects a combination of genetic and epi-genetic self-organisation resulting in emergent properties without a break in continuity. Everything is connected to everything [30].

\section{Conclusion}

Let us hope we have not had the last word or the only word when it comes to the topic of anatomy. This short paper is offered as a means to promote new discussions, debate and further research to support or nullify accepted paradigms in anatomy and fascia. Accepted models and language are the rocks upon which the study of anatomy is built. 'Vertebral column' is an example of an inappropriately named structure when clearly it is not a column. Columns are gravity dependent and cannot, as humans can with our vertebral structure, withstand being, tilted or turned upside down. The notion of an autonomous, isolated tendon working independently from the integration of a wider fascial singularity leaves our understanding of human anatomy and motion lacking. The study of anatomy is underpinned by paradigms which need to be questioned and challenged, otherwise, we are sentenced to a life of $17^{\text {th }}$ century anatomy. Man as machine. Biotensegrity-Anatomy for the $21^{\text {st }}$ Century calls for a new description of muscles [i.e. Latin musculus: little mouse], joints [i.e. pin-joints], cartilage [i.e. a shock absorber], contraction [i.e. to shrink], to allow for a better understanding of wholistic anatomy rather than the current model of isolated parts. Understanding that the self-developed embryo is whole, without interruption to its continuity, leads to the patent conclusion of the fascia singularity. Empowered with the vison of a fascial singularity supported by anatomical and embryological knowledge of the fascia will allow for less invasive surgery and therapeutic interventions at a distance from the source of pain [31].

\section{References}

[1]. Ingber DE. Tensegrity-based mechanosensing from macro to micro. ProgBiophysMol Biol. 2008 Jun-Jul;97(2-3):163-79.Pubmed PMID: 18406455.

[2]. Ingber DE. Tensegrity and mechanotransduction. J BodywMovTher. 2008 Jul 1;12(3):198-200.

[3]. Pittenger MF, Discher DE, Péault BM, Phinney DG, Hare JM, Caplan AI. Mesenchymal stem cell perspective: cell biology to clinical progress. npjRegen Med. 2019 Dec 2;4(22):1-5.

[4]. Sharkey J. Biotensegrity- The Structure of Life: Fascia, Function and Medical Applications. Edited by Lesondak, D., Akey, M, A. CRC Press, Taylor and Francis Group. 2020; Chapter 8, Pages 99-113.
[5]. Fuller RB. Synergetics: Explorations in the geometry of thinking. Estate of R. Buckminster Fuller; 1975.

[6]. Levin SM. The icosahedron as the three-dimensional finite element in biomechanical support. InProceedings of the Society of General Systems Research Symposium on Mental Images, Values and Reality, 1986 May 26 ; 30.

[7]. Sharkey, J. Should bone be considered fascia: Proposal for a change in taxonomy of bone-a clinical anatomist's view. 2020b. International Journal of Biological and Pharmaceutical Science Archive.

[8]. Sharkey, J. Biotensegrity-Fascia and the fallacy of biomechanics. Journal of Australian Association of Massage therapists. 2015.

[9]. Avison, Joanne. Yoga, Fascia Anatomy and Movement. 2015, Handspring Publishing.

[10]. Hall BK. The neural crest as a fourth germ layer and vertebrates as quadroblastic not triploblastic. Evol Dev. 2000 Jan-Feb;2(1):3-5.Pubmed PMID: 11256415.

[11]. Gilbert SF, Epel D. Ecological developmental biology: integrating epigenetics, medicine, and evolution.2009.

[12]. Yoshinaga K. A historical review of blastocyst implantation research. Biol. Reprod. 2018 Jul 1;99(1):175-95.

[13]. Tani, S., Chung, Ui.,Ohba, S. et al. Understanding paraxial mesoderm development and sclerotome specification for skeletal repair. 2020. ExpMol Med 52, 1166-1177.

[14]. Blechschmidt E. The ontogenetic basis of human anatomy: a biodynamic approach to development from conception to birth. North Atlantic Books; 2004.

[15]. van der Wal, Jaap. FASCIA, FABRICA OR FABRIC -On the Origin of Fascia. 2020

[16]. Petrescu L. Descartes on the heartbeat: The Leuven affair. Perspect Sci. 2013 Dec;21(4):397-428.

[17]. Purslow PP. Muscle fascia and force transmission. J BodywMovTher. 2010 Oct 1;14(4):411-7.

[18]. Miyagoe-Suzuki Y, Asakura A, Suzuki M. Skeletal Muscle Cells Generated from Pluripotent Stem Cells.2017.

[19]. Su X, Lyu Y, Wang W, Zhang Y, Li D, Wei S, et al. Fascia origin of adipose cells. Stem Cells. 2016 May 1;34(5):1407-19.

[20]. Calvino N. Connective tissue: Vascular and hematological (blood) support. J. Chiropr. Med. 2003 Dec 1;2(1):25-36.

[21]. Zambidis ET, Peault B, Park TS, Bunz F, Civin CI. Hematopoietic differentiation of human embryonic stem cells progresses through sequential hematoendothelial, primitive, and definitive stages resembling human yolk sac development. Blood. 2005 Aug 1;106(3):860-70.Pubmed PMID: 15831705.

[22]. Habbal O. The Science of Anatomy: A historical timeline. Sultan Qaboos Univ. Med. J. 2017 Feb;17(1):e18-e22.

[23]. Descartes R, Gröber G. Discours de la méthode: 1637. Heitz; 1905.

[24]. Hernández AG, Rodríguez MD, Pi OF, González AC. La influencia de Descartes en el desarrollodelmétodoanatomoclínico. Neurología. 2010 Jul 1;25(6):374-7.

[25]. Jay GD, Waller KA. The biology of lubricin: near frictionless joint motion. Matrix Biol. 2014 Oct 1;39:17-24

[26]. Sharkey J. Biotensegrity focused Thiel Soft Fixed Dissection Course. [2019] Department of Anatomy and Human Identification, College of Life Sciences, University ofDundee, Scotland.

[27]. Scarr G. Biotensegrity-the structural basis of life, 2nd edition.. Handspring Publishing.2018

[28]. Torres, Assis, Andre Koch. Archimedes, the Center of Gravity, and the First Law of Mechanics: The Law of the Lever. 2nd Ed. 2010. Aperion: ISBN: 9780986492648 .

[29]. https://www.merriam-webster.com/dictionary/fulcrum.

[30]. Sharkey, J. Should bone be considered fascia: Proposal for a change in taxonomy of bone- a clinical anatomist's view. Int. j. pharm. biol. sci. arch. 2020.

[31]. Sharkey, J. Site-Specific Fascia TuningPegsandPlacesof Perilous PassageMyofasciaConsiderationsin Upper Extremity Entrapment Neuropathies -A Clinical Anatomists View. Int J Anat Res. 2020.

[32]. Tozzi P. Selected fascial aspects of osteopathic practice. J BodywMovTher. 2012 Oct;16(4):503-19.Pubmed PMID: 23036882.

[33]. Davis, M. The Poetry of Philosophy - 1999. On Aristotle's Poetics, St Augustine's Press.

[34]. Marshall A, Lozeva S. Questioning the theory and practice of biomimicry. Int J Des Nat Ecodyn. 2009 Mar 6;4(1):1-10. 